\title{
The impact of mobile customer relationship management (mCRM) on sales collaboration and sales performance
}

\author{
Michael Rodriguez ${ }^{1}$. Stefanie Boyer ${ }^{2}$
}

Revised: 14 July 2020 / Published online: 1 August 2020

() Springer Nature Limited 2020

\begin{abstract}
In our study, a measure of Mobile CRM (mCRM) is adapted and applied to salespeople in a business-to-business sales context. We propose a research model that integrates Technology Acceptance Model and DeLone and McLean's IS success model to investigate the impact mCRM has on sales performance. Relationships with sales business process, traditional CRM use, collaboration and sales performance are conceptualized and tested. Results suggest that sales performance is highest when digital tools such as mCRM are supported by sales process. Results also suggest that mCRM impacts the relationship performance with customers when collaboration mediates the relationship. Overall, the research empirically demonstrates that mCRM plays an important role in traditional CRM adoption and in sales performance when sales process capabilities and collaboration are involved.
\end{abstract}

Keywords Mobile $\cdot$ CRM $\cdot$ Analytics $\cdot$ Sales $\cdot$ Sales performance

\section{Introduction}

In response to COVID-19 virus, many companies are moving towards working in a more virtual environment. This has placed a focus on organizations embracing collaboration tools and practices to support the virtual workplace. The use of mobile technology has changed the digital landscape to support sales force professionals' ability to access to customer and increase customer engagement. To quote pioneers of sales technology research "the nature of exchange processes between buyers and sellers in business markets has changed dramatically" (Hunter and Perreault 2007 p. 16). Organizations around the world are supporting BYOD model (bring your own device) in order to provide mobile tools that enable sales professionals to better serve their customers and prospects. Sales force automation tools in the form of mobile Customer Relationship Management (mCRM) are increasing productivity and collaboration for sales professionals (Rodriguez and Trainor 2016). mCRM, which are

Michael Rodriguez

mrodriguez@campbell.edu

1 Lundy-Fetterman School of Business, Campbell University, Buies Creek, NC, USA

2 Bryant University, 1150 Douglas Pike, Smithfield, RI, USA
CRM functions that are accessible via a mobile application, provides sales people the ability to gain access to customer information more efficiently (Sinsalo et al. 2015).

Sales professionals are always discovering new ways to leverage information technology to increase efficiency, effectiveness and sales productivity (Hunter and Perreault 2007). Despite the attention and investment on traditional CRM, adoption rate is still relatively low amongst CRM users (Cruz-Jesus, Pinheiro and Oliveira 2019).

In order to stay competitive, sales professionals need to be equipped with tools that enable them to access customer information and be more productive in today's virtual sales environment. Initiatives supporting the mobile movement were listed as the top 15 most significant investments (Kappelman et al. 2014). These investments, which compliment traditional CRM technology, enable sales managers and their team to work remotely with customers and prospects while efficiently responding to their needs (Ranjan and Bhatnagar 2009). The push for mCRM is to enable sales to fill the gaps that exist with traditional CRM limitations. These limitations include static information and the inability to access information offline. mCRM provides several advantages over traditional CRM. These advantages include mobile communication, the ability to manage customer information and $3 \mathrm{G}$ mobile technologies, which enable sales to expand virtual, 
work capabilities. The biggest benefit is having CRM technology functions right at your fingertips.

Although there is abundance of research on traditional CRM technology and its impact on sales performance (Hunter and Perreault 2007; Ahearne et al. 2008; Rodriguez and Honeycutt. 2011; Petrescu and Krishen 2017), there is limited empirical research focused on the area of mCRM; especially from a sales perspective. Most of the current research on mCRM has been studied from an IS perspective (Garrido-Moreno and Padilla-Meléndez, 2011; $\mathrm{Li}$ and Mao 2012; Kim et al. 2015). Beyond the conceptual model provided by Rodriguez and Trainor (2016), the current sales technology literature is limited in empirically testing mCRM's impact on sales performance. Another unique contribution of the research is how mCRM can positively impact the use of other sales technologies such as traditional CRM. The study also looks at the importance of collaboration and sales process and its relationship to mCRM..

The purpose of this research is to develop and test a conceptual model that explains mCRM's impact on collaboration, traditional CRM adoption and individual sales performance. Using technology acceptance model (TAM) as the foundation we analyze mCRM's impact and the moderating relationship sales process has on collaboration. From an Information Systems (IS) success model perspective (Delone and Mclean 1992, 2003, 2004), the study also looks at the mediating impact collaboration has on relationship performance. This study contributes to the sales technology literature by adapting a measure of sales technology use from a mobile perspective. The objective of the study is to build off the wealth of research in IS and apply it in today's virtual sales environment. Our first step in the research is to present the theoretical background from the perspective of technology acceptance model (TAM) and Delone and McLean's IS success model. Next we present the developed model of mCRM and its influence on sales process and sales performance. Theoretical and managerial implications of the results are provided to discuss the impact mCRM has on sales organizations, sales process and future performance.

\section{Theoretical framework and conceptual model}

\section{Sales technology adoption and mCRM use}

Drawing on Hunter and Perreualt's research on Sales Technology (ST) use, "ST refers to Information Technologies (IT) that can facilitate or enable the performance of sales tasks. We view ST tools as spanning the entire gamut of ITs that salespeople use to perform their roles, not just the subset designed as sales CRM or SFA tools" (p. 17, 2007). Past research on information system use has been founded on adoption models such TAM and TAM2 (Davis 1989; Garrido-Moreno and Padilla-Melendez 2011). Technology acceptance model TAM (Davis 1989) and TAM2 (Venkatesh and Davis 2000) serve as a foundation for sales technology research (Avlonitis and Panagopoulos 2005) and is defined as a system theory focusing on technology adoption and use from an individual perspective. The adoption of technology is motivated by an individual's perception and ease of use of the technology (Venkatesh and Davis 2000). Ease of use is defined as "the degree to which a person believes that using a particular system would be free from effort" (Davis 1989, p. 187).

The developed model (Fig. 1) looks at how mCRM, from a salesperson perspective, impacts collaboration and relationship performance and how collaboration moderates that relationship. Before diving into the model, it is important to understand there are differences between traditional CRM and mobile CRM (mCRM). Though both can be assessed via the Internet. The experience in accessing customer information and tracking sales activity can be quite different (Negahban et al. 2016). mCRM enables sales professionals, from a mobile application, to more efficiently use the CRM technology due to its ease of use and functionality. We provide a more detailed comparison of traditional CRM vs. mCRM later in the study.

Fig. 1 Hypothesized framework

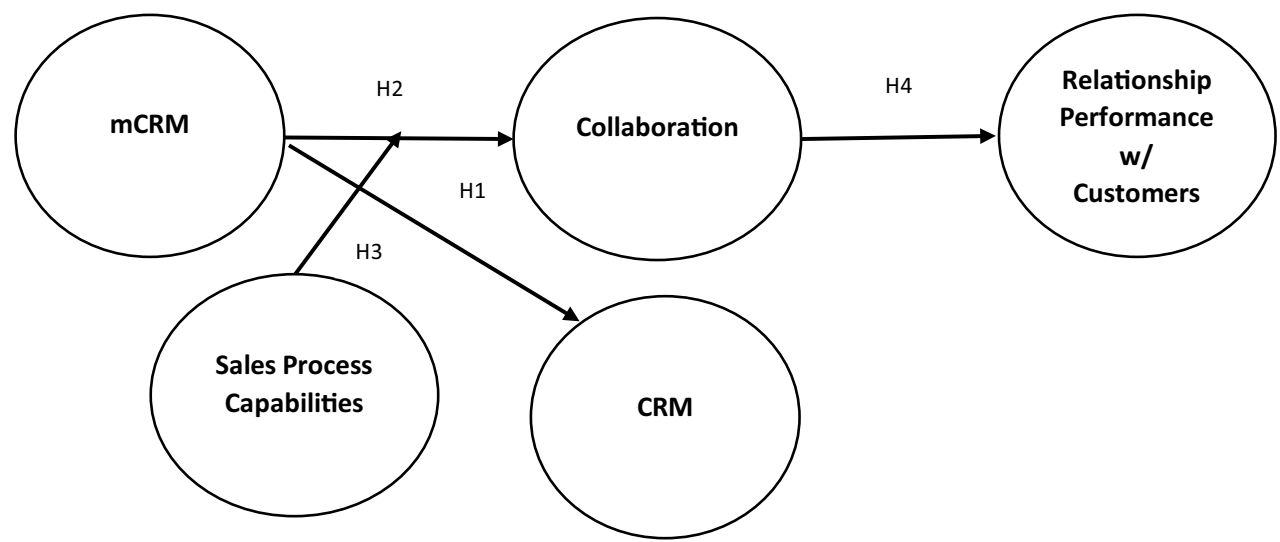


A challenge well documented within the sales technology literature is motivating the sales force to use ST tools (Venkatesh and Davis 2000; Hunter and Perreault 2007; Rodriguez et al. 2014). Traditional CRM solutions, i.e., Salesforce.com, SAP have been well documented in sales technology and practitioner research. Though the investment in sales innovations such as CRM has increased over the years, adoption and use of CRM technology seems to be an existing obstacle within the sales process. Most recent research has looked at the effectiveness of mCRM technology on performance due to ease of use and perceived benefits (Kim et al. 2015). The evolution of having access to customer information right at the sales professionals' fingertips has gone from Web 2.0 (browser based) to mobile application. More organizations have supported CRM from a mobile application perspective due to the ability to access customer information in a virtual environment (Kim et al. 2015). Utilizing TAM as the theoretical foundation, the model below (see Fig. 1) describes the impact mobile CRM technology has on specific areas of the sales process for the sales professional.

More specifically, the study builds on the current sales technology literature and provides a definition to an innovative tool used in today's sales process; mCRM. We theorize the impact mCRM has on accessing customer information, collaborating internally, and as a result increasing sales performance.

\section{Information systems (IS) success}

To analyze the value of mCRM from a sales professional perspective, we employ IS success model as the theoretical foundation. Based on theoretical IS success model developed by Delone and McLean 2003), IS activities in the form of mobile CRM technologies can assist employees in efficiency and effectiveness in the workplace. The IS framework conceptualizes and evaluates different factors of technology resources that impact performance (Vazifehdust and Shahnavazi 2012). Those factors include system and information quality, user satisfaction and net benefits. The model is also applicable at the individual level in which mCRM can improve collaboration amongst internal stakeholders (Delone and Mclean 2003). Kim et al.'s research (2015) adapted the IS model on mCRM's effects on employee performance and found positive relationships between use and user satisfaction with net benefits. To the best of our knowledge, this is the only study empirically testing the impact of mCRM from a sales person perspective.

The goal of this study is to contribute to the evolution of sales technology utilization by developing and testing a model that analyzes mCRM's role in the sales process and its impact on relationship performance. The research draws from the IS literature and theoretical models utilized in sales technology literature such as technology acceptance model (TAM) and IS success model. The study also discusses how collaboration and sales process capabilities integrate with mCRM use. As Fig. 1 illustrates, mCRM technology will have an impact on collaboration, which is moderated by sales process capabilities. The model also explains the relationship between mCRM and sales performance, which is mediated by collaboration.

\section{Traditional CRM}

Different areas of the organization use CRM technology in order to effectively manage customer data (Ahearne et al. 2005). This enables sales professionals to provide customer focused solutions and as a result increases sales. CRM systems are enterprise-wide solutions that support organizations' operational functions such as sales, marketing and service (Raman et al. 2006). Analytical functions are also available in CRM by providing the ability to analyze customer trends and better serve those clients based on their needs (Rodriguez and Trainor 2016). The main objective of traditional CRM is to help sales organizations increase customer satisfaction and provide value through positive customer experiences (Payne and Frow 2005). The use of CRM has been well documented in practice and in research (Hansotia 2002; Peltier et al. 2013) but successful implementation has had mixed results. One of the major challenges in CRM implementation has been user adoption (Nguyen and Waring 2013). The value CRM technology provides "is largely dependent on whether or not salespeople are using the system and adding information about customers, accounts, opportunities" (Rodriguez and Trainor 2016, p. 77). The lack of user adoption is due to the challenge of integration of three different perspectives: technology, business process, and human factor (Chen and Popovich 2003). Failure of CRM can be due to both organizational and technical issues (Goodhue et al. 2002). From the technology perspective we look at the impact CRM, from a mobile perspective, may have on traditional CRM use.

\section{From traditional to mobile CRM (mCRM)}

According to Rodriguez and Trainor " $\mathrm{mCRM}$ is designed to be accessed and operated via a mobile device, such as a smartphone or tablet, and enables sales professionals to not only access customer and prospect information but also update sales activities anytime, anywhere in real time" (2016, p. 68). Traditional CRM (i.e., desktop or browser based) that is accessible from a sales professional's device is able to fill the gaps of the limitations of traditional CRM. mCRM enables sales professionals, from a mobile application, to more efficiently use the CRM technology due to its ease of use and functionality. 
Another unique aspect of mCRM is the real time location based services (LBS) provided by mobile technology. LBS, similar to a GPS, enable sales professionals to locate customers and prospects in real time (Steimer and Steimer 2008). This advanced technology provides database synchronization, which delivers real time information to internal stakeholders (i.e., marketing, customer service, management (Karjaluoto et al. 2014). Through the use of mCRM customer interactions are recorded in real time ensuring accurate recording of activities and providing sales professionals customer data right at their fingertips (Garrido-Moreno and Padilla-Meléndez 2011; $\mathrm{Li}$ and Mao 2012). mCRM enables a more interactive and personal dialogue with customers and prospects, therefore improving knowledge sharing of customers' needs.(Verma and Verma 2013). mCRM makes it faster to collect valuable information on prospects and customers in real time. Using mCRM also enables salespeople to maximize productivity by having functionality such as calendar and contact access from as salesperson's mobile device. The end user has the convenience of accessing detailed information and scheduling appointments right at their fingertips. The alternative entails opening up a laptop, connecting to a wireless network, connecting to a browser, then logging into traditional CRM.

The availability of CRM from a mobile application can increase the use of CRM technology and the number of recorded sales activities. The migration of Internet users from desktop to mobile devices means people now expect real time information to be available from anywhere. Internet traffic from mobile devices grew from $7 \%$ in 2009 to almost 53\% (Statista.com 2020). Sales and non-sales employees are no longer tied to their desks; especially in today's move from office to virtual work environment. A mobile CRM strategy provides employees to work on the go and provides the ability for those out on the field to access schedules and sales data in a virtual environment. A recent research found that empowering employees with mobile technologies could help sales organizations gain an extra $240 \mathrm{~h}$ of work annually (Clement 2020).

With access of customer data right at the sales professionals' fingertips, customer interactions are captured in real time, forecasting is updated and as a result traditional CRM is more effective. As salespeople record data, the CRM system becomes more useful from an analytic and strategic perspective to both salespeople and sales managers (Rodriguez and Trainor 2016).

Therefore, the use of mCRM can lead to increased use of traditional CRM from other CRM users (i.e., sales, marketing, service). Therefore, we propose:

H1 mCRM adoption will have a positive relationship with a firm's CRM system utilization.

\section{mCRM and collaboration}

Adoption of mCRM though is not enough. The innovation has to provide real return in terms of productivity and relationship performance. "Although models of behaviors precede estimates on economic returns, managers need to advance and test models that link a salesperson's uses of technologies to his or her conduct of desirable tasks" (Hunter and Perrault 2007, p. 18). Another reason for failed use of CRM technology is due to employees' lack of knowing the benefits of the technology and its impact (Nguyen et al. 2007). If employees, both sales and non-sales, understand the benefits of technologies, internal communication can be streamlined and customer experience enhanced (Barac et al. 2017). To respond to the demands and needs of customers, sales professionals are relying on business-tobusiness technologies (B2B) to increase internal collaboration between sales and their peers (Lee and Qualls 2010). Collaboration is defined as "the process by which professionals conform to a standardized way of working, developing and improving their routine via increased communication or streamlined procedure" (Rodriguez and Trainor 2016, p. 76). Tjosvold's found that collaboration between departments resulted in "improved productivity, enhanced competence, and increased confidence in work relationships" (1988, p. 287). The use of mCRM technology combined with integrated sales processes develops a unique human capability that realizes increased sales performance (Coltman 2007). With the increase in complexity of client needs and expectations, sales relies on different departments such as marketing, management, service and pre-sales support during different stages of the sales process. The evolution of traditional CRM to mCRM provides sales professionals greater flexibility in collaboration with others due to the access to client information. mCRM enables sales professionals and other internal stakeholders to see each other's interactions with customers in real time. The efficiency of internal communication is increased due to sales having the ability to update client activity while face-to-face with the customer. As a result, colleagues who are in other locations (i.e., office or other client locations) or working virtually can respond faster to requests that will impact the sales process. Therefore, we propose:

H2 mCRM will have a positive relationship with collaboration.

\section{The Influence of Sales Process Capabilities}

It is an imperative front-line customer facing professionals define their business process prior to implementing technology. "A well-defined business process combined with organizational alignment are components of a successful 
technology initiative within a sales firm" (Rodriguez et al. 2016, p. 368). A sales organization's process capability refers to the ability to follow a specific number of stages that increases the probability of a closed sale and as a result leads to increased sales performance. The ability to follow a sales process that is formalized and repeatable can help in achieving sales performance goals. Past research on sales technology innovation has found a strong relationship between technology use and sales process (Hunter and Perreault, 2007). For example, research on the use of traditional CRM has helped sales representatives in the sales process by shortening sales cycles and improving close ratios (Stoddard et al. 2006; Ahearne et al. 2007). Similar research on social media in business-to-business (B2B) sales, has also found that a positive correlation between sales process and social CRM technology (Trainor et al. 2014). As with past technology initiatives (i.e., traditional CRM), the investment in technology may not have a direct effect on sales performance. In our study we explore the impact sales process capability has on the use of mobile CRM solutions. Specifically, we look at whether sales process capability enhances the relationship between $\mathrm{mCRM}$ and collaboration. Internal collaboration and information sharing via mCRM are enhanced through the ability in having a well-defined sales process. Therefore, we propose:

H3 Sales process capability will moderate the relationship between mCRM and collaboration.

\section{mCRM Impact on Sales Performance}

Research on the use of sales technology and its impact on performance have been well documented (Hunter and Perreault 2007; Ahearne et al. 2007; Rapp et al. 2008; Ramaraj 2010; Peltier et al. 2013). Sale professionals' ability to achieve sales goals is greatly enhanced by technology solutions such as CRM (Hunter and Perreault 2006; Rodriguez and Honeycutt 2011). Technology in the form of mCRM may enable sales executives to access client information and deliver a solution that meets the client's needs more efficiently. Therefore, resulting in increased sales performance. In Delone and McLean's revised IS model, the authors analyze the impact of technology on net benefits from an individual perspective (2004). In our model, we specifically look at the relationship level of performance, which focuses on the strength of the relationship with customers and increased customer retention (Hunter and Perreault 2006). Relationship-building performance with customers is defined as "the degree to which the sales professional develops deeper customer relationships by understanding the client's unique needs and providing a solution that meets those needs" (Rodriguez and Trainor 2016, p. 78). Understanding customer needs and matching those needs to one's product/service is an imperative part of the sales process. Hunter and Perreault (2007) define this stage as "the extent to which salespeople apply information and knowledge to construct and propose recommendations that are mutually beneficial to both the selling and the buying firms" (p. 20). Sales professionals share information internally to develop solutions for prospects by uncovering needs, documenting sales activities and proposing a customized product/service that meets the need of the potential customer. Utilization of mCRM enables sales organizations to capture customer interactions, improve data quality (Gorla et al. 2010) and collaborate internally with other departments such as marketing, service or management in real time. The capabilities and functionality provided by $\mathrm{mCRM}$ will enable salespeople to complete relationship-forging activities and exchange information with colleagues immediately. Past research has found though that the link between sales technology use and performance is not always direct (Hartline et al. 2000). Technology innovation such as MCRM will lead to improved behaviors that impact sales performance. Collaboration between departments can increase the ability of sales professionals to deliver an enhanced customer experience and therefore lead to increased performance. "Effectively managing customer data is crucial for the success of mCRM systems, because customers' information is a critical part of an organization's profitability and competitiveness" (Negahban et al. 2016, p. 754). Sales technology can develop deeper relationships with customers through improved information sharing and communication. Therefore, we propose:

H4 The relationship between mCRM adoption and relationship performance with customers will be mediated by collaboration.

\section{Methodology}

To assess sales professionals' use of mCRM, we adapted Hunter and Perreault's sales technology scale and pre-tested to validate the revised measure. Our objective is to explore the relationships between the mCRM measure and the other constructs discussed in the model via partial least squares (PLS) regression analysis. We then test the hypotheses with a larger sample size to analyze the moderating effect of sales process capabilities and the mediating effect of collaboration between mCRM and relationship performance. Measures in the study came from existing research in order to maintain the integrity of past studies.

\section{Assessment of mCRM Scale-pre-test}

Utilizing industry contacts from LinkedIn, 86 online surveys were distributed to a convenience sample of outside, business-to-business sales professionals in the U.S. The target 
audience was individuals with titles of account managers, account executives, and sales directors, which represent the approximate target sample for this study. Personal LinkedIn messages were sent with 61 of the surveys completed, yielding a $71 \%$ response rate. 15 of the respondents were female $(25 \%)$ and 46 were male $(75 \%)$.

\section{Measures}

As previously discussed, the mCRM measure was developed utilizing the sales technology measure from Hunter and Perreault (2007). The phrase "sales technology" was replaced with mobile CRM in measuring sales professionals' ability to access, analyze and communicate information. We utilized a 3 item, seven-point Likert scale for the adapted measure.

The CRM utilization scale is based on the adapted measure from Rodriguez and Honeycutt (2011). The measure combined several studies on technology usage (Hunter and Perrault 2007), perceived benefits of CRM, and technology adoption (Jelinek et al. 2006). CRM Utilization is based on nine Likert-type items on a seven-point scale anchored by "Strongly Disagree" (1) and "Strongly Agree" (7).

The scale measuring collaboration was also utilized from Rodriguez and Honeycutt's research on CRM use and collaboration (2011). It consists of five Likert-type items set to a seven-point scale anchored by "Strongly Disagree" (1) and "Strongly Agree" (7).

Performance with customers was measured utilizing the sales performance scale developed by Behrman and Perreault (1982). Performance with customers is based on four Likert-type items set to a 7-point scale anchored by "Needs improvement" (1) and "Outstanding" (7).

\section{Discussion of measure assessment}

The objective of the pre-test was to assess the adapted mCRM construct from a sales technology use perspective and assess the relationships between all the measures. The results show a highly reliable measurement for all scales as indicated in Table 1 below. Cronbach's alpha exceeded the minimum levels determined by past research (Fornell and Larcker 1981). Convergent validity and internal consistency

Table 1 Scale reliability and validity

\begin{tabular}{llll}
\hline & Cronbach's alpha & $\begin{array}{l}\text { Composite reli- } \\
\text { ability }\end{array}$ & AVE \\
\hline COLLAB & 0.729 & 0.843 & 0.704 \\
CRM & 0.704 & 0.747 & 0.539 \\
RPC & 0.796 & 0.761 & 0.613 \\
mCRM & 0.963 & 0.87 & 0.868 \\
\hline
\end{tabular}

of the measures were also examined. Average variance extracted (AVE) of all measures exceeded the recommended minimum of 0.5 (Gefen and Straub 2005).

The pre-test also analyzes the conceptualization of mCRM and its relationship with several constructs: Collaboration, utilization of traditional CRM and relationship performance with customers. Utilizing Partial Least Squares (PLS) to examine the relationships, the analysis confirms the positive relationship between mCRM and the 3 constructs. Table 2 summarizes correlations amongst the constructs. The results suggest that the relationships proposed for study are theoretically sound.

Regression analysis confirmed that MCRM was positively correlated with collaboration, CRM and relationship performance with customers. These results suggest that mCRM has positive impact in the sales process and the relationships hypothesized for the analysis are theoretically sound.

\section{Hypothesis testing}

The second data collection was performed by collecting responses from an online convenience sample on LinkedIn. Using the same approach as in the pre-test, the target audience was individuals with titles of account managers, account executives, and sales directors. Personal LinkedIn messages were sent to 215 outside sales professionals. Of the 215 surveys returned, 127 were deemed usable yielding a response rate of 59\%. The survey assured that all responses were completely confidential. The respondents, all from outside, business-to-business (B2B) sales, represented a number of different industries (Table 3).

Of the 127 responses, $66 \%$ were male which is similar to the national averages according to the Bureau of Labor

Table 2 Path coefficients correlation

\begin{tabular}{ll}
\hline Relationship & Path coefficient \\
\hline mCRM-> Collaboration & $.267^{*}$ \\
mCRM-> CRM & $.297^{*}$ \\
mCRM-> Relationship Performance with Custom- & $.320^{*}$ \\
ers & \\
\hline$* \mathrm{p}<.05$ &
\end{tabular}

Table 3 Respondents industry profile

\begin{tabular}{lc}
\hline Industry sector & Percent \\
\hline Technology & 48 \\
Consulting/Services & 23 \\
Medical & 12 \\
Financial & 10 \\
Manufacturing & 7 \\
Total & 100
\end{tabular}


Statistics (Cunningham 2019). Tests were conducted to rule out any potential nonresponse bias by comparing early responders vs. those that answered the survey several weeks later.

\section{Measure reliability and validity assessment}

To measure the reliability and validity of the constructs we applied exploratory factor analysis (EFA) with maximum likelihood extraction with oblique rotation for the 28 items. As per Kaiser-Meyer-Olkin Measure (KMO) sampling adequacy (0.761) and Bartlett's test (Snedecor and Cochran 1989) of sphericity $(1995.582, \mathrm{p}<0.000)$, the correlation matrix analysis provided evidence to move forward with further factor analysis.

The variables utilized (mCRM, CRM, collaboration, and relationship performance with customers) were existing constructs adapted from past studies. The new construct introduced to the model, sales business process, was measured using a five-item scale to assess a sales organization's use of an established and repeatable sales process. Sample questions included "We consistently follow a standard process to qualify opportunities". In order to examine construct validity, confirmatory factor analysis in SmartPLS (Ringle et al. 2005) was utilized. Table 4 reports the CFA loadings of each measurement item on the latent construct. Several indicators were eliminated due to not meeting the recommended level of 0.7 , SBP 4 and 5 for sales business process and COLL1 for collaboration. COLL3 was very close to the threshold at 0.689 and was kept in the model.

As shown in Table 4, the standardized loadings ranged from 0.689 to 0.947 and all loadings were significant with t-values larger than 2.00. Results from the CFA analysis exhibited an acceptable fit of the measurement model $(X 2=468.57$ (126), p < 0.01, Root Mean Square Error

Table 4 Confirmatory factor analysis

\begin{tabular}{|c|c|c|}
\hline Factor items & Std. loadings & t-values \\
\hline \multicolumn{3}{|l|}{ Mobile CRM } \\
\hline mCRM1 I extensively use my mobile (CRM) application on mobile device to perform my job & $.944 *$ & 53.138 \\
\hline mCRM2 Compared to others in sales, I am oriented in the mobile CRM application & $.908 *$ & 40.368 \\
\hline mCRM3 I consider myself a frequent user of my mobile CRM application & $.962 *$ & 81.778 \\
\hline mCRM4 I fully utilize the capabilities of my mobile CRM application on my mobile device & $.944 *$ & 54.556 \\
\hline mCRM5 I have completely integrated the mobile CRM application into my sales process & $.964 *$ & 80.333 \\
\hline mCRM6 I consistently use my Mobile CRM application to track and record sales activities & $.935^{*}$ & 49.294 \\
\hline \multicolumn{3}{|l|}{ Collaboration } \\
\hline COLL2 I communicate with my colleagues on proposed solutions for my clients & $.819 *$ & 11.721 \\
\hline COLL3 I consistently share client information with others in the company & $.689 *$ & 5.322 \\
\hline COLL4 Communicating client needs is important in winning business & $.925 *$ & 36.542 \\
\hline COLL5 Communicating client needs is important for client retention & $.938 *$ & 43.561 \\
\hline COLL6 Communicating client needs is important in achieving customer satisfaction & $.905 *$ & 23.235 \\
\hline COLL7 I communicate with my sales manager regarding potential sales opportunities & $.785^{*}$ & 9.484 \\
\hline \multicolumn{3}{|l|}{ Sales business process } \\
\hline SBP1 We consistently use a formal process for measuring customer satisfaction & $.842 *$ & 5.428 \\
\hline SBP 2 We consistently follow a standard process to qualify opportunities & $.947 *$ & 6.377 \\
\hline SBP3 Specific criteria have been established to define a strategic account in our company & $.827 *$ & 5.610 \\
\hline \multicolumn{3}{|l|}{ CRM utilization* } \\
\hline CRM1 I extensively use Customer Relationship Management (CRM) technology to perform my job & $.840 *$ & 5.023 \\
\hline CRM2 Compared to other in sales, I am oriented in the CRM system I utilize & $.884 *$ & 6.796 \\
\hline CRM3 I consider myself a frequent user of my company's CRM technology & $.879 *$ & 6.261 \\
\hline CRM4 I fully utilize the capabilities of our CRM system & $.900 *$ & 8.132 \\
\hline CRM5 I have completely integrated the CRM application into my sales process & $.871 *$ & 8.075 \\
\hline \multicolumn{3}{|l|}{ Relationship performance with customers } \\
\hline RPC1 Listening attentively to identify and understand the real concerns of your customers & $.838 *$ & 22.171 \\
\hline RPC2 Building your customer's business with your products & $.866^{*}$ & 23.370 \\
\hline RPC3 Working out solutions to a customer's questions or objections & $.848^{*}$ & 15.883 \\
\hline RPC4 Working with customers to help them improve their profitability to both firms & $.794 *$ & 13.950 \\
\hline
\end{tabular}

$* \mathrm{p}<0.01$ 
of Approximation [RMSEA] $=0.08$, Normal Fit Index $[\mathrm{NFI}]=0.759$ ).

To evaluate internal consistency reliability and convergent validity, Cronbach's Alpha and average variance extracted (AVE) were calculated which are summarized in Table 5:

Cronbach's Alpha all met the threshold of 0.70 (Nunnally 1978) and AVE measures all exceeded the recommended level of 0.50 (Gefen and Straub 2005). Tests for discriminant validity were also found to be acceptable based on Fornell and Larcker tests (1981). Based on the above analysis, the measurement model indicates acceptable reliability and validity.

\section{Common method variance}

To evaluate common method bias in the data, Harman's post hoc one-factor test was used (MacKenzie and Podsakoff 2012). Principal components factor analysis extracted factors that had Eigenvalues greater than one. The first factor explained $27 \%$ of the variance in the data, indicating that a single factor does not account for most of the variance. Consequently, it is proper to assume that common method bias did not impact the data.

\section{Analytical strategy}

To evaluate the relationships within the model, SmartPLS software (Ringle et al. 2005) was utilized. PLS was applied since it requires fewer statistical specifications and data constraints than the covariance-based strategy of LISREL. There are several advantages to utilizing PLS over other regression methods. First, PLS accommodates the need for multiple-regression when the sample size is relatively small (Cassel et al. 2000). PLS smaller samples are acceptable as long as the sample size is at least five times larger than the number of items contained in one of the major constructs which is met in this research study as the largest construct, collaboration, has six items. Second, simulation studies that compare PLS with covariance-based SEM confirm that PLS path modeling is particularly suitable as a means to avoid improper solutions and in research that focuses on prediction

Table 5 Scale reliability and validity

\begin{tabular}{llll}
\hline & Cronbach's alpha & $\begin{array}{l}\text { Composite } \\
\text { reliability }\end{array}$ & $\begin{array}{l}\text { Average variance } \\
\text { extracted (AVE) }\end{array}$ \\
\hline CRM & 0.83 & 0.742 & 0.766 \\
Collaboration & 0.81 & 0.731 & 0.698 \\
RPC & 0.759 & 0.703 & 0.7 \\
SBP & 0.751 & 0.782 & 0.79 \\
mCRM & 0.875 & 0.88 & 0.889 \\
\hline
\end{tabular}

(Reinartz et al. 2009), as is the case in this research. Lastly, PLS is capable of handling independent variables with multi-collinearity (Marcoulides 1998; Wold 1982).

\section{Evaluation of structural model-direct effect}

To test the structural equation model in PLS, a hierarchical process was followed to test the direct relationship, the moderating effect of sales business process and the mediating effect of collaboration on relationship performance with customers. With a larger and more diverse sample size, the results show that mCRM has a positive relationship with CRM use $(\beta=0.305, p<0.01)$, therefore $\mathrm{H} 1$ was supported. The relationship between mCRM and collaboration had a correlation of $-0.144(p<.01)$. Therefore H2 was not supported.

\section{Evaluation of structural model—indirect effect}

To examine the interactive effect of sales business process, hierarchical regression in SmartPLS was utilized where collaboration was the dependent variable and MCRM and sales business process were both mean centered. The multiplicative interactive term between the constructs were calculated to measure the impact of the interaction.

The analysis of interaction within $\mathrm{mCRM}$ and sales business process showed that there was a positive effect on collaboration $(\beta=0.305, p<.01)$, therefore $\mathrm{H} 3$ was supported. The analysis also plotted the relationship between mCRM and collaboration with sales business process. As depicted in Fig. 2, the greatest effect on mCRM has on collaboration is when sales business process is present.

\section{Mediating effect of collaboration on relationship performance with customers}

As previously discussed, the relationship between technology and performance is not always direct (Trainor et al. 2014). In order to test the mediating effect of collaboration between mCRM technology and performance we utilize a procedure from Mathieson et al.'s work on TAM (2001) to compare two models: one model with the direct link between mCRM and relationship performance with customers and the second model that includes collaboration. In the first model, mCRM was regressed with relationship performance which was significant with a beta coefficient of $0.135(p<0.01)$. The second model where collaboration was included tested the indirect effect on relationship performance yielded a beta coefficient of $0.413(p<0.01)$. To assess the change in explained variance in $R^{2}$ of relationship performance the "pseudo F-test" was calculated. The statistic is calculated by multiplying $f 2$ by $n-k-1$. Applying this procedure (Mathieson, Peacock and Chin 2001), the $f 2$ for 
Fig. 2 Moderating impact of sales business process
Moderating Effect 1

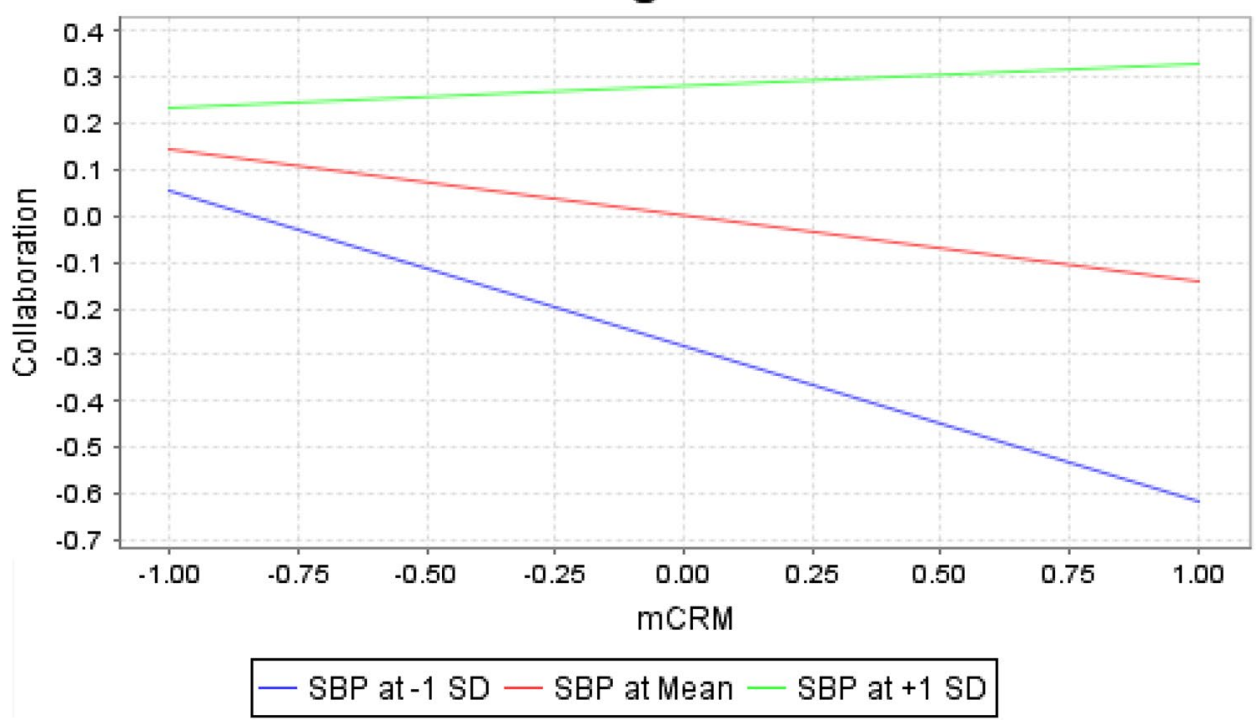

Table 6 Mediating effect of collaboration

\begin{tabular}{lllc}
\hline & R2 & F2 & Pseudo F-test \\
\hline Direct model & .018 & .019 & 2.299 \\
Mediating model & .171 & .206 & 13.794 \\
\hline
\end{tabular}

the increased variance explained in relationship performance is significant as shown in Table 6.

The calculation shows that collaboration mediates the connection between mCRM and relationship performance. Therefore $\mathrm{H} 4$ is supported.

\section{Theoretical implications}

The empirical study provides several contributions to sales technology research. Grounded in the Technology Acceptance Model (TAM) and IS Success Model, the study outlines the impact and benefits of using mobile CRM (mCRM) in today's virtual sales environment. TAM theory focuses on technology adoption and the perceived benefits from the use of sales tools such as mCRM applications. First, the development of the measure mobile (mCRM) and its relationships with collaboration, sales process and traditional CRM were evaluated to help evolve the discussion on the use of sales technology in the sales process. The study found that mCRM, has a positive relationship with the use of traditional CRM. Though there has been a plethora of research on the use of traditional CRM, sales user adoption has been a challenge (Ullah et al. 2020). Due to real time access of customer information via mCRM, there is an increased benefit of traditional CRM therefore reinforcing the theory of technology adoption.
The study found the relationship between MCRM and collaboration was not supported. Though CRM from a mobile application perspective has shown ease of use to capture customer data, it may not help in internal collaboration. As previously discussed, collaboration was defined as the process in which colleagues standardized the way of working and communicating together. Since the use of mCRM is one-way communication this probably explains the lack of significance between the constructs.

The second contribution of the study was the impact of sales process capability. The study concluded that the construct moderates the relationship between mCRM and collaboration. This supports past research, which has found that the link between sales technology use and performance is not always direct (Hartline et al. 2000).

Third, the study adds to the theoretical basis of IS success model (Delone and McLean 2003) given that technology is vital to sales performance. The study's findings identified that the relationship between mCRM adoption and relationship performance with customers is mediated by collaboration.

Lastly, from a theoretical perspective, the study provides a much-needed foundation of the use of technology in a virtual sales environment. With the evolution of technology, increase in work-life-family balance, and the impact COVID-19 has made in the sales ecosystem, it is imperative more scholarly research is committed to how virtual technology (i.e., web conferencing and mobile) can benefit both sales professionals and its customers. Though there are still many challenges and questions to technology adoption, the ever-changing landscape provides a unique opportunity for researchers to make an impact. 


\section{Implications for practice}

The COVID-19 pandemic has changed forever how sales professionals interact with customers (Hartmann and Lussier 2020). The purpose of this study was to examine how CRM technology, from a mobile application perspective, impacts today's virtual sales professional.

With the evolution of sales technology and the need for working virtually, the utilization of mobile applications has not only played a role in the business environment but also the customer engagement process. Sales focused organizations must help support their front-line sales professionals by embracing virtual collaboration tools and practices.

The findings empirically support the overall objective of our study in that mCRM delivers benefits to sales professionals in their sales process. It's important to keep in mind that technology initiatives needs to start with defining the sales process first. Many technology projects, such as traditional CRM, fail due to companies not having a well-defined sales process (Rodriguez et al. 2012). The sales process plays in integral role in sales users understanding the benefits of technology when it supports and complements that process.

Another challenge firms are faced with is the lack of CRM adoption (Homburg et al. 2010). Due to the ease of use and access of mCRM functionality, sales people utilize the tool more often. This drives stakeholders (marketing, support, management) within the firm to use traditional CRM as well. Due to the real time impact mCRM provides, the data in traditional CRM are more reliable, which leads to others using traditional CRM functions such as analytics, forecasting and pipeline management.

Lastly the study looked at how collaboration mediates the connection between mCRM and relationship performance. With the real time function of knowing customers' needs, mCRM provides the sales force to adapt to those needs and share them with others (i.e., service, management, marketing, etc.).

Sales organizations that have embraced future of work practices are well positioned to adapt to the current demands of COVID-19 and thrive during these uncertain times. With the increase of supporting a virtual customer engagement environment, companies need to provide resources and technologies to support new behavioral norms. Expanding virtual work capabilities and available tools such as mCRM not only support collaboration and sales productivity, but also create an ecosystem that enables their sales forc to thrive in uncertain times and ensure customer success.

\section{Limitations and directions for future research}

Due to the exploratory nature of this research, the study has several limitations. First, the mCRM construct measures the use of mobile CRM application from an individual perspective and not the firm perspective. Future research can measure the relationship of mobile with other firm performance measures such as sales, customer acquisition, customer retention or lead-to-customer ratio. Second the responses are self-reported. Other research can also connect the use of mCRM from the buyers' perspectives. Another limitation is lack of controls for the study. Though many of the respondents had similar characteristics, future research may focus on how characteristics such as age, gender or salesperson tenure may impact mCRM use and compare any differences. Lastly, the sample size is small. Though PLS methodology was implemented in the study, which enables analysis to be done with a lower number of responses, more data collection is needed.

This study provides a foundation for a more comprehensive research framework to better understand the phenomenon of mCRM application capabilities in the sales organization. In our study we only discussed the use of mCRM from customer data perspective. As technology evolves, mCRM has deeper capabilities in areas of analytics, artificial intelligence (AI) and forecasting. In response to the COVID pandemic and the move to work virtually, we hope that both academia and practice can work together to create resilience for future uncertainty and apply future of work research that are already under exploration.

\section{Compliance with ethical standards}

Conflict of interest On behalf of all authors, the corresponding author states that there is no conflict of interest.

\section{References}

Ahearne, M., E. Jones, A. Rapp, and J. Mathieu. 2008. High touch through high tech: The impact of salesperson technology usage on sales performance via mediating mechanisms. Management Science 54 (4): 671-685.

Ahearne, M., D.-E. Hughes, and N. Schillewaert. 2007. Why sales reps should welcome information technology: Measuring the impact of CRM-based IT on sales effectiveness. International Journal of Research in Marketing 24 (4): 336-349.

Ahearne, M., R. Jelinek, and A. Rapp. 2005. Moving beyond the direct effect of SFA adoption on salesperson performance: Training and support as key moderating factors. Industrial Marketing Management 34 (4): 379-388. 
Avlonitis, G.J., and N.G. Panagopoulos. 2005. Antecedents and consequences of CRM technology acceptance in the sales force. Industrial Marketing Management 34 (4): 355-368.

Barac, Dusan, Vanjica Ratkovic-Zivanovic, Milica Labus, Suzana Milinovic, and Aleksandra Labus. 2017. Fostering partner relationship management in B2B ecosystems of electronic media Journal of Business and Industrial Marketing, 32 (8), 76-89.

Behrman, D.N., and W.D. Perreault Jr. 1982. Measuring the performance of industrial salespersons. Journal of Business Research 10 (3): 355-370.

Cassel, C.M., P. Hackl, and A.H. Westlund. 2000. On measurement of intangible assets: A study of robustness of partial least squares. Total Quality Management 11 (7): 897-907.

Chen, I.J., and K. Popovich. 2003. Understanding customer relationship management (CRM). Business Process Management Journal 9 (5): 672-688.

Clement, J. 2020. Share of Global Website Traffic 2015-2020 https ://www.statista.com/statistics/277125/share-of-website-trafficcoming-from-mobile-devices/.

Coltman, Tim. 2007. Can Superior CRM Capabilities Improve Performance in Banking? Journal of Financial Services Marketing 12 (2): 102-114.

Cruz-Jesus, Frederico, Andreia Pinheiro, and Tiago Oliveira. 2019. Understanding CRM adoption stages: Empirical analysis building on the TOE framework. Computers in Industry 109: 1-13.

Cunningham, E. 2019. Professional certifications and occupational licenses: Evidence from the Current Population Survey. Monthly Labor Review, 1-38. Retrieved June 15, 2020, from www.jstor .org/stable/26743923

Davis, F.D. 1989. Perceived usefulness, perceived ease of use, and user acceptance of information technology. MIS Quarterly 13 (3): 319-340.

Delone, W.H., and E.R. Mclean. 2004. Measuring e-commerce success: Applying the DeLone and McLean information systems success model. International Journal of Electronic Commerce 9 (1): 31-47.

DeLone, W.H., and E.R. McLean. 1992. Information systems success: The quest for the dependent variable. Information Systems Research 3 (1): 60-95.

Delone, W.H., and E.R.E. McLean. 2003. The DeLone and McLean model of information systems success: A ten-year update. Journal of Management Information Systems 19 (4): 9-30.

Garrido-Moreno, A., and A. Padilla-Meléndez. 2011. Analyzing the impact of knowledge management on CRM success: The mediating effects of organizational factors. International Journal of Information Management 31 (5): 437-444.

Fornell, C., and D.F. Larcker. 1981. Structural equation models with unobservable variables and measurement error: Algebra and statistics. Journal of Marketing Research 18: 382-388.

Gefen, D., and D. Straub. 2005. A practical guide to factorial validity using PLS-Graph: Tutorial and annotated example. Communications of the Association for Information systems 16 (1): 5 .

Goodhue, D.L., B.H. Wixom, and H.J. Watson. 2002. Realizing business benefits through CRM: Hitting the right target in the right way. MIS Quarterly Executive. 2: 79-94.

Gorla, N., T.M. Somers, and B. Wong. 2010. Organizational impact of system quality, information quality, and service quality. The Journal of Strategic Information Systems 19 (3): 207-228.

Hansotia, B. 2002. Gearing up for CRM: Antecedents to successful implementation. Journal of Database Marketing \& Customer Strategy Management 10 (2): 121-132.

Hartline, Michael D., James G. Maxham III, and Daryl O. McKee. 2000. Corridors of influence in the dissemination of customeroriented strategy to customer contact service employees. Journal of Marketing 64 (April): 35-50.
Hartmann, N., and B. Lussier. 2020. Managing the sales force through the unexpected exogenous COVID-19 crisis. Industrial Marketing Management. 88: 101-111.

Homburg, C., J. Wieseke, and C. Kuehnl. 2010. Social influence on salespeople's adoption of sales technology: a multilevel analysis. Journal of the Academy of Marketing Science 38 (2): 159-168.

Hunter, G.K., and W.D. Perreault Jr. 2006. Sales technology orientation, information effectiveness, and sales performance. Journal of Personal Selling and Sales Management. 26 (2): 95-113.

Hunter, G.K., and W.D. Perreault Jr. 2007. Making sales technology effective. Journal of Marketing. 71 (1): 16-34.

Jelinek, R., M. Ahearne, J. Mathieu, and N. Schillewaert. 2006. A longitudinal examination of individual, organizational, and contextual factors on sales technology adoption and job performance. Journal of Marketing Theory and Practice 14 (1): 7-23.

Karjaluoto, H., A. Töllinen, J. Pirttiniemi, and C. Jayawardhena. 2014. Intention to use mobile customer relationship management systems. Industrial Management and Data Systems. 114 (6): 966-978.

Kappelman, L., E. Mclean, J. Vess, and N. Gerhart. 2014. The 2014 SIM IT key issues and trends study. MIS Quarterly Executive. 14: 237-263.

Kim, Changsu, In-Seok Lee, Tao Wang, and Mirsobit Mirusmonov. 2015. Evaluating effects of mobile CRM on employees' performance. Industrial Management and Data Systems 115 (4): $740-764$.

Lee, J.L., and W.J. Qualls. 2010. A dynamic process of buyer-seller technology adoption. Journal of Business and Industrial Marketing. 25 (3): 220-228.

Li, L., and J.Y. Mao. 2012. The effect of CRM use on internal sales management control: An alternative mechanism to realize CRM benefits. Information and Management. 49 (6): 269-277.

MacKenzie, S.B., and P.M. Podsakoff. 2012. Common method bias in marketing: Causes, mechanisms, and procedural remedies. Journal of Retailing 88 (4): 542-555.

Marcoulides, G.A. 1998. Quantitative methodology series: Modern methods for business research. Mahwah, NJ: Lawrence Erlbaum Associates.

Mathieson, Kieran, Eileen Peacock, and Wynne W. Chin. 2001. Extending the technology acceptance model: The influence of perceived user resources. Database for Advances in Information Systems 32 (3): 86-112.

Negahban, Arash, Dan J. Kim, and Changsu Kim. 2016. Unleashing the power of mCRM: investigating antecedents of mobile CRM values from managers' viewpoint. International Journal of HumanComputer Interaction. 32 (10): 747-764.

Nguyen, T.H., J.S. Sherif, and M. Newby. 2007. Strategies for successful CRM implementation. Information Management \& Computer Security 15: 102-115.

Nguyen, T.H., and T.S. Waring. 2013. The adoption of customer relationship management (CRM) technology in SMEs: An empirical study. Journal of Small Business and Enterprise Development. 20 (4): 824-848.

Nunnally, J.C. 1978. Psychometric Theory, 2ndd ed. New York: McGraw-Hill.

Payne, A., and P. Frow. 2005. A strategic framework for customer relationship management. Journal of Marketing 69 (4): 167-176.

Peltier, J., D. Zahay, and A.S. Krishen. 2013. A hierarchical IMC data integration and measurement framework and its impact on CRM system quality and customer performance. Journal of Marketing Analytics 1 (1): 32-48.

Petrescu, M., and A.S. Krishen. 2017. Marketing analytics: From practice to academia. Journal of Marketing Analytics 5: 45-46.

Raman, P., C.M. Wittmann, and N.A. Rauseo. 2006. Leveraging CRM for sales: The role of organizational capabilities in successful 
CRM implementation. Journal of Personal Selling and Sales Management. 26 (1): 39-53.

Ramaraj, P. 2010. Information systems flexibility in organizations: Conceptual models and research issues. Global Journal of Flexible Systems Management. 11 (1): 1-12.

Ranjan, J., and V. Bhatnagar. 2009. A holistic framework for mCRMData mining perspective. Information Management and Computer Security 17 (2): 151-165.

Rapp, A., R. Agnihotri, and L.P. Forbes. 2008. The sales force technology-performance chain: The role of adaptive selling and effort. Journal of Personal Selling \& Sales Management 28 (4): 335-350.

Reinartz, W., M. Haenlein, and J. Henseler. 2009. An empirical comparison of the efficacy of covariance-based and variancebased SEM. International Journal of Research in Marketing 26: 332-344.

Ringle, C.M., Wende, S. and S. Will. 2005. SmartPLS 2.0 (M3) Beta, Hamburg.

Rodriguez, Michael, Haya Ajjan, and Robert Peterson. 2016. Social media in large sales forces: An empirical study of the impact of sales process capability and relationship performance. Journal of Marketing Theory and Practice. 24 (3): 365-379.

Rodriguez, Michael, and Kevin Trainor. 2016. A conceptual model of the drivers and outcomes of mobile CRM application adoption. Journal of Research in Interactive Marketing. 10 (1): 67-84.

Rodriguez, M., A. Dixon, and J. Peltier. 2014. A review of the interactive marketing literature in the context of personal selling and sales management: A research agenda. Journal of Research in Interactive Marketing. 8 (4): 294-308.

Rodriguez, M., and E. Honeycutt. 2011. CRM's impact on b2b sales professionals' collaboration and sales performance. Journal of Business-to-Business Marketing. 18 (4): 335-356.

Rodriguez, M., R.M. Peterson, and V. Krishnan. 2012. Social media's influence on business-to-business sales performance. Journal of Personal Selling and Sales Management. 32 (3): 365-378.

Sinisalo, J., H. Karjaluoto, and S. Saraniemi. 2015. Barriers to the use of mobile sales force automation systems: A salesperson's perspective. Journal of Systems and Information Technology. 17 (2): 121-140.

Snedecor, George W., and Witiiam G. Cochran. 1989. Statistical methods, 8thEdn. Ames: Iowa State Univ. Press Iowa 54: 71-82.

Steimer, F.L., and T. Steimer. 2008. Future mobile CRM-A specific kind of collaboration (concepts for the automotive and tourist area). In 2008 2nd IEEE international conference on digital ecosystems and technologies, 115-118.

Stoddard, J.E., S.W. Clopton, and R.A. Avila. 2006. An analysis of the effects of sales force automation on salesperson perceptions of performance. Journal of Selling and Major Account Management 6 (1): 38-56.

Tjosvold, D. 1988. Cooperative and competitive interdependence collaboration between departments to serve customers. Group and Organization Management. 13 (3): 274-289.

Trainor, Kevin, James Andzulis, Adam Rapp, and Raj Agnihotri. 2014. Social media technology usage and customer relationship performance: A capabilities-based examination of social CRM. Journal of Business Research. 67 (1): 1201-1208.
Ullah, A., S. Iqbal, and S.R. Shams. 2020. Impact of CRM adoption on organizational performance. Competitiveness Review: An International Business Journal. https://doi.org/10.1108/ CR-11-2019-0128.

Vazifehdust, H., and A. Shahnavazi. 2012. Investigation critical success factors of customer relationship management implementation. World Applied Sciences Journal. 18 (8): 1052-1064.

Venkatesh, V., and F.D. Davis. 2000. A theoretical extension of the technology acceptance model: Four longitudinal field studies. Management Science. 46 (2): 186-204.

Verma, D., and D.S. Verma. 2013. Managing customer relationships through mobile CRM in organized retail outlets. International Journal of Engineering Trends and Technology. 4 (5): 1696-1701.

Wold, H. 1982. Soft modeling: The basic design and some extensions. In Systems under indirect observations: Causality, structure, prediction, ed. H. Wold and K.G. Joreskog. Amsterdam: Elsevier.

Publisher's Note Springer Nature remains neutral with regard to jurisdictional claims in published maps and institutional affiliations.

Michael Rodriguez serves as a lecturer at Campbell University's Lundy-Fetterman School of Business teaching Business Analytics, Sales, and Digital Marketing. Dr. Rodriguez earned his PhD in Technology Management at Stevens Institute of Technology in Hoboken NJ where he won "Outstanding Dissertation Award" for his research on CRM. His research interests include sales, analytics and cross cultural negotiations. His work has been published in the Journal of Business Research, Journal of Personal Selling and Sales Management, Industrial Marketing Management, Journal of Research in Interactive Marketing, Journal of Selling, and Journal of Business to Business Marketing.

Stefanie Boyer has a $\mathrm{PhD}$ from University of South Florida and is an Associate Professor at Bryant University. She created a sales program at Bryant University and is currently Director of the Northeast Intercollegiate Sales Competition (NISC), which brings together the brightest sales students and leading sales organizations for networking, recruiting, and skill-building. Dr. Boyer has won several teaching, research and service awards over the years including the prestigious Academy of Marketing Science Sales Sig Annual Excellence in Teaching Award in August, 2017. Her research work which focuses on self-directed learning, sales and social media have been published in the Journal of Business Research, Journal of the Academy of Marketing Science, Journal of Selling, Journal of Self-Directed Learning, Marketing Management Journal, Journal of Marketing Channels, Journal of Business to Business Marketing, Journal of Marketing Education, Journal for Advancement of Marketing Education, Academy of Marketing Studies Journal, International Journal of Sales, Marketing and Retailing, and the Journal of Research and Interactive Marketing. 